\title{
Documentação ortodôntica: novos aspectos de uma antiga preocupação
}

\author{
Robert Willer Farinazzo Vitral*, Marcio José da Silva Campos**, Cleverson Raymundo Sbarzi Guedes ${ }^{\star \star \star}$
}

Nos últimos anos, tem aumentado a preocupação com a quantidade de raios $\mathrm{X}$ à qual os pacientes são expostos durante os exames radiográficos solicitados pelos dentistas responsáveis por seus tratamentos. Essa preocupação tem sido observada nas entidades de referência em Ortodontia em todo o mundo. Prova disso é o editorial, publicado em 2008 ${ }^{1}$, no qual o então editor do American Journal of Orthodontics and Dentofacial Orthopedics (AJO-DO), David Turpin, analisou as orientações da British Orthodontic Society ${ }^{2}$ (BOS) para a realização de radiografias em Ortodontia. Em suas considerações gerais, a BOS basicamente lembra que não é conhecido nenhum nível seguro de exposição à radiação e recomenda uma análise criteriosa, para cada exame radiográfico, da relação risco/benefício para a saúde do paciente, devendo tais exames ser indicados quando houver uma justificativa clínica apropriada. Desse modo, segundo a BOS, não haveria indicação e/ou necessidade de realização de radiografias em Ortodontia nos seguintes casos: radiografias feitas rotineiramente antes dos exames clínicos; conjunto de radiografias de rotina para todos os pacientes ortodônticos; exame periapical completo pré-tratamento;

Como citar este artigo: Vitral RWF, Campos MJS, Guedes CRS. O que há de novo na Odontologia - Documentação ortodôntica: novos aspectos de uma antiga preocupação. Dental Press J Orthod. 2011 July-Aug;16(4):15-8. radiografia cefalométrica de perfil para predição do crescimento facial; radiografia de mão e punho para previsão do surto de crescimento; radiografias de rotina das articulações temporomandibulares para avaliação de disfunções; radiografias com finalidade médico-legal; radiografias finais com único objetivo de avaliação profissional ou para apresentação clínica; e tomografia computadorizada de feixe cônico (TCFC) como exame de rotina.

A atenção dispensada à exposição à radiação foi intensificada com a popularização dos exames de TCFC na Odontologia, tornando esse exame o novo foco de atenção. Em novo editorial de $2010^{3}$, Turpin descreveu um projeto da European Atomic Energy Community, o SEDENTEXCT, que estabeleceu normas provisórias para a indicação desses exames em Odontologia - enquanto obtém informações chave para a elaboração científica de orientações do uso clínico da TCFC. Já nos Estados Unidos, a American Association of Orthodontists e a American Association of Maxillofacial Radiology uniram-se com o objetivo de elaborar um documento de referência ${ }^{4}$ que orientará sobre qual técnica de diagnóstico por imagem é mais útil em condições ortodônticas específicas, uma

" Os autores declaram não ter interesses associativos, comerciais, de propriedade ou financeiros, que representem conflito de interesse, nos produtos e companhias descritos nesse artigo.

\footnotetext{
* Mestre e Doutor em Ortodontia pela Universidade Federal do Rio de Janeiro. Professor Associado da Universidade Federal de Juiz de Fora. Coordenador do Programa de Pós-Graduação em Saúde da UFJF. Coordenador do curso de especialização em Ortodontia da UFJF.

** Especialista em Saúde Coletiva e em Ortodontia pela Universidade Federal de Juiz de Fora. Mestre e Doutorando em Saúde na Universidade Federal de Juiz de Fora. Professor Convidado do curso de especialização em Ortodontia da UFJF.

*** Mestre em Direito, Estado e Cidadania pela Universidade Gama Filho/Rio de Janeiro. Doutor em Ciências Jurídicas e Sociais pela Universidad del Museo Social Argentino, Buenos Aires/Argentina. Professor Adjunto da Universidade Federal de Juiz de Fora.
} 
vez que temos à disposição da Ortodontia uma variedade de tecnologias de imagem que vão da radiografia cefalométrica à TCFC. Turpin recomendou que, enquanto esses documentos ainda não estão concluídos, o ortodontista deve usar a TCFC com cautela e sempre se perguntar se a questão clínica pode ser respondida através de exames radiográficos convencionais.

No Brasil, ainda não existem recomendações específicas sobre a utilização de exames radiográficos na Ortodontia, tampouco uma mobilização de entidades de classe ou governamentais para criá-las. O que se verifica, habitualmente, é a realização de um conjunto de exames iniciais e finais ${ }^{5}$, assim como exames de reestudo solicitados quando o profissional sente a necessidade de avaliar o tratamento já realizado, para definir os próximos passos.

Associada ao interesse clínico de diagnóstico, planejamento e avaliação do tratamento quando da solicitação dos exames, uma preocupação legal se faz presente, visto que a Ortodontia é uma atividade que, na sua relação de prestação de serviços, pode ter por objeto obrigações de resultado ${ }^{6}$. O profissional se obriga a atingir um determinado resultado útil com sua atividade, sendo a documentação ao final do tratamento prova irrefutável de uma conduta clínica bem realizada. Além disso, durante um processo civil movido contra um ortodontista, se faz necessária a comprovação da existência de um suposto dano causado ao paciente para que seja caracterizado um nexo causal (relação de causa e efeito) com a conduta profissional, o que poderia ou não ser comprovado nas documentações obtidas durante o tratamento ${ }^{7}$. O Código de Defesa do Consumidor ${ }^{8}$, por sua vez, em seu artigo $6^{\circ}$, possibilita ao julgador a inversão do ônus da prova, fazendo com que o profissional tenha que comprovar que não agiu culposamente, evidenciando o prejuízo para o profissional caso esses exames não estejam disponíveis para perícia.
Diferentemente do que se vê nos Estados Unidos e em países da Europa, no Brasil, o Ministério Público tem tomado a posição que naqueles países tem cabido às associações de classe, e se pronunciado dando recomendações sobre as indicações e contraindicações dos exames radiográficos. A reportagem "Uso indiscriminado dos raios $\mathrm{X}$ pode levar à instauração de processos éticos”, apresentada no Jornal do $C R O M G^{9}$, mostra-nos isso em relação aos planos de saúde.

\section{POSICIONAMENTO E RECOMENDAÇÕES DO MINISTÉRIO PÚBLICO}

A Constituição de 1988 universalizou o acesso à saúde. Depois, vieram a criação do SUS e a regulamentação dos planos e seguros privados de assistência à saúde. Uma das mais significativas marcas da democrática Carta Brasileira foi a facilitação do acesso à Justiça para os cidadãos, para que as demandas individuais ou coletivas batessem à porta do Judiciário. O Promotor de Justiça, representante mais conhecido do cidadão na esfera do Ministério Público, ganhou a responsabilidade de zelar, no âmbito de suas atribuições legais, pela defesa dos usuários dos sistemas público e privado de saúde $^{10}$. Nessa esteira, surgiram várias Promotorias de Justiça especializadas na defesa dos direitos relacionados à saúde.

Dentro desse contexto, nota-se, vez por outra, a atuação de Promotorias de Justiça de Defesa da Saúde na expedição de recomendações aos planos de saúde, médicos ou odontológicos, para evitar abusos de toda sorte. O próprio Conselho Federal de Odontologia, ao expedir a Resolução $\mathrm{n}^{\mathrm{o}} 102 / 2010^{11}$, pretendeu combater o uso indiscriminado dos raios $\mathrm{X}$, com fins exclusivamente ou essencialmente administrativos, para substituir perícias, auditorias ou verificações facilmente exequíveis por outros meios, menos invasivos ou lesivos à saúde dos usuários desses planos. Em sentido semelhante, externou preocupação a Portaria $n^{\circ} 453 / 98$ da Anvisa ${ }^{12}$. 
No mesmo sentido, veio a Recomendação $\mathrm{n}^{\circ}$ 05/2010 ${ }^{13}$ da Promotoria de Saúde de Belo Horizonte, que, sob o pálio da atribuição legal e constitucional, com objetivo de proteção direta à saúde dos usuários de planos de saúde, expediu recomendação para evitar uso abusivo de exames de raios $\mathrm{X}$ em diversos procedimentos odontológicos. A recomendação tem o condão, pois, de atingir dois objetivos: a) os abusos das exigências dos planos de saúde como meio de controle de tratamentos odontológicos; e b) o abuso na utilização dos exames de raios $\mathrm{X}$, potencialmente lesivos à saúde do usuário. Não poderia ser outro o objetivo das manifestações do Ministério Público, mesmo porque isso é explicitado no Plano Nacional de Atuação Ministerial em Saúde Pública ${ }^{14}$.

Parece claro que tal recomendação causa preocupação entre odontólogos das mais diversas especialidades, pois a utilização abusiva não pode ser considerada a regra geral entre os profissionais, e ainda existe um justo receio de instauração de eventuais ações de fundo ético. Pior ainda: uma preocupação com enfrentamento de ações promovidas pelo Ministério Público ou até mesmo por particulares, perante o Judiciário.

O profissional odontólogo não pode ficar à mercê de recomendações múltiplas capazes de tolher a sua forma de atuação, diante de sua especialização ou expertise. Também não pode ficar com receio de promover o controle de um tratamento, através de exame qualquer, para fugir a uma responsabilidade civil, administrativa ou até mesmo criminal ${ }^{15}$.

Por outro lado, o Ministério Público não deve afastar-se de suas atribuições legais com vistas à defesa da saúde, inclusive de expedir recomenda- ções quando necessária e indispensável sua intervenção, preventiva ou não, conforme o artigo 67, inciso VI, da Lei Complementar n ${ }^{\circ}$ 34/94-MG ${ }^{16}$.

Como profissional de saúde, o odontólogo deverá pautar sua atuação na responsabilidade, na ética, na justificativa da intervenção (própria ou de terceiros), com vistas ao êxito do tratamento pretendido ou ajustado. Se existe necessidade de controle através de exames complementares, sejam de raios $\mathrm{X}$ ou outro qualquer, que tal seja feito com base na altivez da relação profissional-paciente, com a documentação precisa, evitando desgastes e um conflito que pode desaguar no Judiciário.

Isso jamais terá o condão de afastar a possibilidade do paciente (cidadão) procurar a Justiça, pelas mais diversas "portas de entrada", porque o acesso ao Judiciário é tratado com garantia fundamental do cidadão ${ }^{17}$.

\section{CONCLUSÃO}

Talvez seja o momento da criação, nas Associações de Ortodontia, de comissões que possam, com base científica e legal, expedir recomendações ou quaisquer atos normativos aos seus associados e credenciados para utilização da radiação ionizante, não somente para a atuação clínica de rotina, mas, também, para o delineamento de pesquisas baseadas no diagnóstico por imagens. Essas Associações devem, ainda, aproximar-se de outras entidades ou instituições, como o próprio Ministério Público, para ajustar atuações conjuntas preventivas, que alcancem finalidades comuns, tais como: fornecer orientação técnica especializada para a atuação do Ministério Público, não inibir a atuação profissional e ser eficaz para coibir o uso abusivo de exames que utilizem raios $\mathrm{X}$. 


\section{REFERÊNCIAS}

1. Turpin DL. British Orthodontic Society revises guidelines for clinical radiography. Am J Orthod Dentofacial Orthop. 2008 Nov:134(5):597-8

2. Provisional guidelines on CBCT for dental and maxillofacial radiology. [Cited $2011 \mathrm{Apr}$ 1st]. Available from: http://www. sedentexct.eu/system/files/sedentexct_project_provisional_ guidelines.pdf.

3. Turpin DL. Clinical guidelines and the use of cone-beam computed tomography. Am J Orthod Dentofacial Orthop. 2010 July; 138(1):1-2.

4. $A A O$ and $A A O M R$ to produce joint position paper on imaging [Cited 2011 Apr 1st]. Available from: http://www.aaomembers.org/ MyPractice/Technology/AAO-Imaging-Initiative.cfm

5. Barroso MG, Vedovello Filho M, Vedovello SAS, Valdrihi HC Kuramae M, Vaz V. Responsabilidade civil do ortodontista após a terapia ortodôntica. RGO: Rev Gaúcha Odontol. 2008;56(1):67-73.

6. Oliveira MLL. Responsabilidade civil odontológica. Belo Horizonte: Del Rey; 2000.

7. Souza NTC. Odontologia e responsabilidade civil. Bol Jurid [Internet]. 2006. [Acesso 2011 Mar 29];4(181). Disponível em: http:// www.boletimjuridico.com.br/doutrina/texto.asp?id=1334.

8. Brasil. Lei n. 8078, de 11 de setembro de 1990. Código de Defesa do Consumidor. Diário Oficial da União. 1990 set 12. [Acesso 2011 Mar 31]. Disponível em: http://www.planalto.gov.br/ ccivil_03/Leis/L8078.htm.
9. Uso indiscriminado dos Raios-X pode levar à instauração de processos éticos. Jornal do CROMG. 2011 fev-mar:XXVIII(201):3-4

10. Mazzilli HN. A defesa dos interesses difusos e coletivos em Juízo. $22^{a}$ ed. São Paulo: Saraiva; 2009

11. Conselho Federal de Odontologia (Brasil). Resolução $n^{\circ}$. 102, de 12 de maio de 2010. Proíbe o uso indiscriminado de Raio X. Diário Oficial da União. 2010 jun 2.

12. Agência Nacional de Vigilância Sanitária (Brasil). Portaria no. 453, de 01 de junho de 1998. Diário Oficial da União. 1998 jun 2.

13. Brasil. Inquérito Civil n. 0024.06.000816-6 - SRU/MPMG.

Promotoria de Justiça de Defesa da Saúde de Belo Horizonte/MG. Recomendação $n^{\circ}$. 05, de 17 de novembro de 2010

14. Plano Nacional de Atuação Ministerial em Saúde Pública (Manual de Atuação). [Acesso 2011 Mar 31]. Disponível em: http://www. mp.mg.gov.br/portal/public/interno/repositorio/id/23377.

15. Oliveira E. Deontologia, erro médico e direito penal. Rio de Janeiro: Forense; 1998.

16. Minas Gerais. Lei Orgânica do Ministério Público de Minas Gerais. (Lei Complementar 34/94). Centro de Estudos e Aperfeiçoamento Funcional do Ministério Público de Minas Gerais. Organizador: Clóvis Tatagiba. Belo Horizonte; 2008.

17. Brasil. Constituição (1988). Constituição da República Federativa do Brasil. Brasília (DF): Senado Federal; 1988. [Acesso 2011 Mar 31]. Disponível em: http://www.planalto.gov.br/ccivil_03/Constituicao/ Constituicao.htm.

Endereço para correspondência

Robert Willer Farinazzo Vitra

Av. Rio Branco 2595/1604

CEP: 36.010-907 - Juiz de Fora / MG

E-mail: robertvitral@acessa.com 